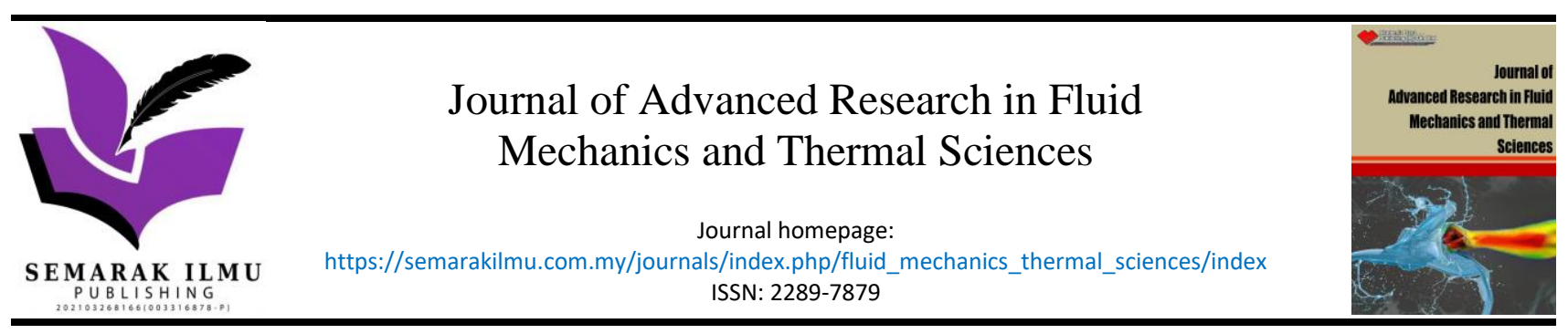

\title{
CFD Analysis on Effect of Angulation in A Healthy Abdominal Aorta-Renal Artery Junction
}

\author{
Pranav Hegde ${ }^{1}$, Gowrava Shenoy B ${ }^{1,}$, S M Abdul Khader ${ }^{1}$, Raghuvir Pai $\mathrm{B}^{1}$, Srikanth Rao $\mathrm{D}^{1}$, \\ Masaaki Tamagawa², Ravindra Prabhu ${ }^{3}$, Nitesh Kumar ${ }^{1}$, Kamarul Arifin Ahmad ${ }^{4}$ \\ 1 Department of Mechanical Engineering and Manufacturing Engineering, Manipal Institute of Technology, Manipal Academy of Higher \\ Education, Manipal, 576104, Karnataka, India \\ 2 Department of Biological Functions Engineering, Graduate School of Life Sciences and System Engineering, Kyushu Institute of Technology, \\ Japan \\ 3 Department of Nephrology, Kasturba Medical College, Manipal Academy of Higher Education, Manipal, Karnataka, India \\ 4 Department of Aerospace Engineering, Universiti Putra Malaysia, Malaysia
}

\section{$\begin{array}{ll}\text { ARTICLE INFO } & \text { ABSTRACT }\end{array}$}

\section{Article history:}

Received 23 April 2021

Received in revised form 19 August 2021

Accepted 25 August 2021

Available online 21 October 2021

\section{Keywords:}

Renal artery bifurcation;

haemodynamics; newtonian flow; flow recirculation; computational fluid dynamics
The recent developments in computational fluid dynamics (CFD) can be useful in observing the detailed haemodynamics in renal artery bifurcation for clinical evaluation and treatment. The present study focuses on haemodynamic behaviour of blood as it flows through the abdominal aorta-renal artery junction in an idealistic healthy artery with varying bifurcation angles to the abdominal aorta, i.e. from $30^{\circ}$ to $90^{\circ}$ with increments of $15^{\circ}$. This is to examine the effect of angulation on the junction and to determine whether arterial geometry plays a role in the prediction of atherosclerotic lesions. The three-dimensional models used in this study were generated using ANSYS WORKBENCH 19.0, and numerical simulation was done using FLUENT 19.0 solver. The blood flow is assumed to be Newtonian, incompressible and laminar. Haemodynamic parameters such as velocity, wall pressure and wall shear stress along with flow variation are compared among the different models. As the angulation increased, velocity and wall shear stress at the ostial region decreased by $14 \%$ and $52 \%$ respectively. Wall pressure at the same region saw an increase by $3 \%$. Therefore, renal arteries with higher bifurcating angles to the abdominal aorta were observed to be more prone to the formation of atherosclerotic lesions. The present study is a precursor for future studies on renal artery with stenosis.

\section{Introduction}

Globally, cardiovascular diseases (CVDs) are the number one cause of death. CVDs are a group of disorders of the heart and blood vessels and include coronary heart diseases, rheumatic disease and other conditions. The World Health Organization (WHO) conducted a survey which shows that over 15 million people in the world suffer from stroke every year [1]. Of those 15 million, $66 \%$ of them die, and the remaining thirty-four per cent are permanently disabled; the primary reason being

\footnotetext{
* Corresponding author.

E-mail address: gowravshenoyb@gmail.com
}

https://doi.org/10.37934/arfmts.88.1.149165 
atherosclerosis [2]. Atherosclerosis is a condition wherein excess amounts of fats, low-density lipoproteins build upon the walls of the arteries reducing blood flow to the kidneys. This is known to lead to hypertension by virtue of the activation of the renin angiotensin system [3]. Analysis of blood flow through these systems remains crucial in understanding these diseases. Blood flows through a variety of regions involving branches, bifurcations, and curvatures in the coronary, abdominal, carotid and femoral vascular systems [4]. Variation in vasculature is known to cause flow variation and flow recirculations, making it prone to cardiovascular diseases [5]. Plaque formation as result of atherosclerosis tend to form adjacent to arterial bifurcation [6]. They exhibit reduced values of haemodynamic parameters such as wall shear stress and play a role in the progression of atherosclerotic lesions [7].

The dependency of these forces on one's lumen geometry is one of the reasons specific individuals are more likely to develop atherosclerosis than others [8]. A study on the haemodynamics of carotid arteries using particle image velocimetry (PIV) elucidates on the effect of geometry, rheology, pulsatility and compliance of carotid arteries on directional wall shear stress and flow behaviour which is proven to cause atherosclerosis [9]. Prominent medical techniques that facilitate the quantification of blood flow in arteries are Doppler ultrasound, Computed Tomography (CT) and magnetic resonance imaging (MRI). Both of these techniques suffer from excessive acquisition times, and their use on diseased arteries are limited. Time-dependant measurement of blood flow using these methods become rather tedious. Thus, paving the way for numerical techniques to predict the haemodynamics of cardiovascular systems and act as a complementary tool during the treatment of cardiovascular diseases [2]. Computational models have been used to obtain a better understanding of the fluid dynamics in arteries [10]. As a result of which there is an increase in demand for noninvasive tools such as computational fluid dynamics (CFD) in the field of medicine and biomedical engineering [11].

Recently, numerical studies are being used to investigate the parameters of blood flow that result in cardiovascular diseases [12]. Certain clinical studies compare steady flow and pulsatile flow in a carotid artery bifurcation ([13]. Results from pulsatile flow conditions in contrast with steady flow conditions show varying regions of separations with time and wall shear stress values. There are also numerical studies regarding pulsatile blood flow in carotid arteries on both normal and stenosed cases. Two separate cases are taken for comparing the blood flow parameters in the stenosed artery with a healthy one [14]. On the other hand, there have been limited studies regarding blood flow in the abdominal aorta and renal artery junction. Much needed emphasis is required in this region as atherosclerosis of renal artery can lead to renovascular hypertension and ischemic stroke [15]. Stenosis formation in renal arteries results in a lower amount of blood flow to the kidney, leading to an increase in blood pressure in the region [16]. It accounts for $7 \%$ of peripheral vascular diseases and is one of the leading causes of secondary hypertension [17]. With the help of CFD and MRI/CT images, the formation of atherosclerotic lesions can be accurately predicted, and haemodynamic parameters can be assessed [19]. Feasibility of incorporating data obtained from CT/MRI in numerical studies is demonstrated in [20]. A potential risk factor of artery geometry resulting in exaggerated atherosclerosis was investigated [21]. A similar study on the femoral region was conducted proving that aortic bifurcation angle was an independent factor for aortoiliac occlusive disease - which is a case of stenosis of iliac arteries. Agitated haemodynamics, particularly low and oscillatory wall shear stress is identified as a prominent determinant in the development and progression of atherosclerotic lesions in regions of arterial bifurcation [22]. The effect of angle of renal artery angulation was also investigated employing a device known as ostium flow diverter, which is capable of altering blood flow to the kidneys by changing the angle of renal artery bifurcation. Essential 
parameters like flow recirculation and WSS vary proportionally with the increase in diverter length and [23].

Comprehension of renal artery stenosis requires proper acumen regarding the flow behaviour of blood in normal, healthy arteries. Emphasis on the effect of angulation, considering few angles, on flow recirculation in abdominal aorta-renal artery junction has been investigated [24]. In the present study, a fundamental investigation is done on the effect of angulation of renal artery branches in a healthy idealistic abdominal aorta, with renal artery bifurcation angles ranging from $30^{\circ}$ to $90^{\circ}$. It is an extension of the study carried out in [25], with the scope of the angles widened. In this analysis, the angle of the renal artery to the abdominal aorta is varied to analyse the flow dynamics. Simulation on an idealistic model assists in focusing on the effect of angulation while removing all other aspects of the geometry such as curvature and bends. Haemodynamic parameters such as velocity, wall pressure and wall shear stress (WSS) along with flow recirculation are determined. Velocity gradients determine the region, area and length of flow recirculation in the system [26]. Wall pressure (pressure exerted on the arterial wall) validates the velocity and is used to correlate to arterial wall thickening [27]. WSS is an important parameter which can help predict the extent of stenosis in a particular region [28]. This study can aid the nephrologists to analyse flow dynamics in an ideal abdominal aorta and renal artery [18]. Numerical simulation methods thus help in the haemodynamic analysis, and the results of the idealistic case can be used for comparison of arteries with stenosis.

\section{Methodology}

\subsection{Theory}

Blood flow in this vascular model is assumed to be to Newtonian, laminar and incompressible. By doing so, emphasis on the viscous effects of the blood flow can be clearly analyzed in the bifurcation. zone. The governing equation used was the Navier-Stokes's equation for incompressible flows [29].

$\nabla \cdot v=0$

$\rho\left(\frac{\partial v}{\partial t}+v \cdot \nabla v\right)=-\nabla p+\mu \nabla^{2} v$

where $\rho$ is the density, $\mu$ is the viscosity of blood, $v$ is the velocity vector, $\operatorname{simplified}$ as $u=u\left(\hat{e}_{x}\right)+v\left(\hat{e}_{y}\right)$ $+z\left(\hat{e}_{z}\right)$ and $p$ is the pressure. Eq. (1) depicts the law of conservation of mass, for a system having no sources or sinks obtained from applying continuity equation on density, an intensive property. Eq. (2) is the modified equation for the law of conservation of momentum i.e. Newton's second law.

\subsection{Modelling}

The model used in this study was that of an idealistic abdominal aorta with symmetric renal artery branches, obtained from the mid slice of a CT image of a healthy renal artery. CT data was used to generate the 3D model in ANSYS Design Modeler, which was later on subjected to surface refining and clean up [4]. Figure 1(a) shows the configuration of one of the models with the renal artery bifurcation angle of $30^{\circ}$ from the abdominal aorta's axis. The entire body was split into five zones, $A$, $B, C, D$ and $E$ as depicted in figure $1(b)$ in order to obtain optimum mesh quality. A hybrid hexahedraltetrahedral mesh used is shown in figure 2. Zone $A$ and $E$ represent the upper and lower part of the abdominal artery, respectively, whereas zone $B$ illustrates the region of bifurcation. Zone $C$ and $D$ 
represent the left and right renal artery, respectively. For the purposes of realistic simulation, the diameter ratio of the abdominal aorta to the renal arteries were significantly higher.

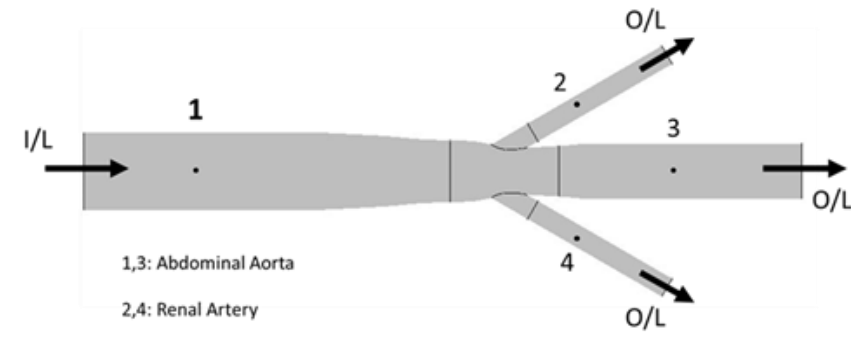

(a)

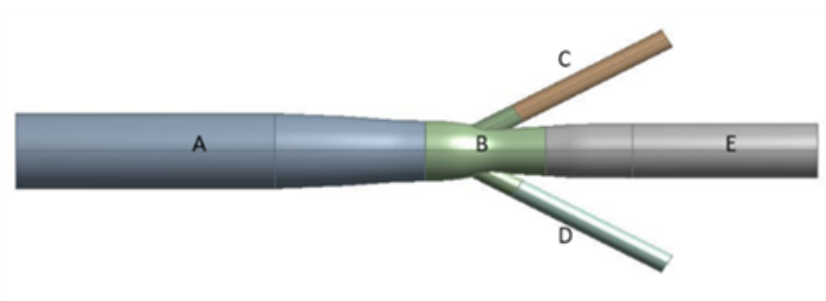

(b)

Fig. 1. (a) plane view of the abdominal aorta with renal artery bifurcation as $30^{\circ}$ and b) depicts mesh zones for the same

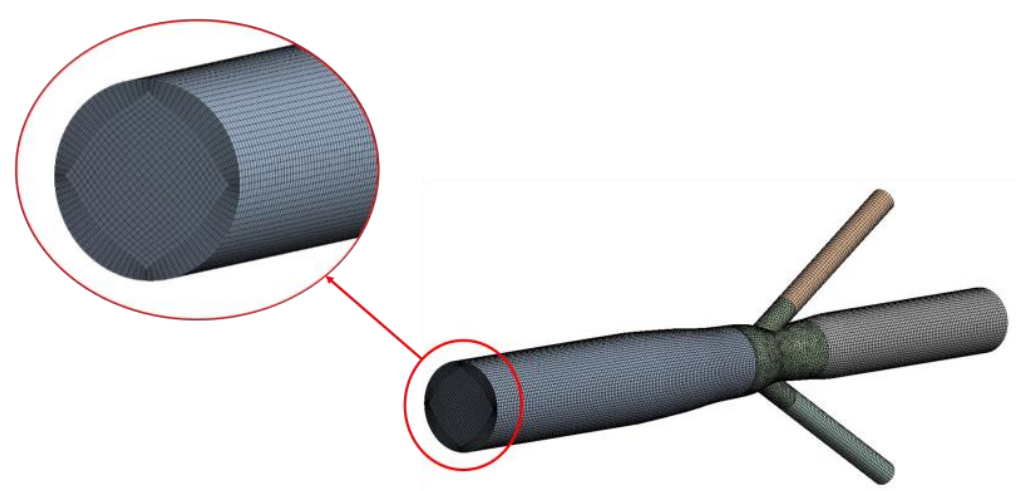

Fig. 2. Hybrid mesh of abdominal aorta model with $45^{\circ}$ angle renal artery angulation

\subsection{Analysis}

The blood flow simulation was done in all the five models under transient and laminar conditions using the Finite Volume discretisation method, with blood being considered as Newtonian and incompressible fluid [30,31]. Pulsatile nature of the blood flow was simulated with the help of a userdefined function with velocity at the inlet and pressure at the outlets as parameters. Grid dependency tests were conducted for one of the models; artery with $30^{\circ}$ bifurcation under steady-state condition. Under steady-state conditions, the meshes of a varying number of elements of the artery model were solved whilst the velocity and pressure parameters were being monitored. The changes in the refinement of the mesh are done considering the solver capacity and computational times. The sections used to monitor the properties are illustrated in Figure 3. Static velocity of magnitude 0.2 $\mathrm{m} / \mathrm{s}$ obtained from the early systolic velocity profile was taken as the inlet velocity boundary condition. Outlet pressure of $90 \mathrm{~mm} \mathrm{Hg}$ was taken as the outlet boundary condition. The sections used to observe Figure 4 shows the variation velocities in section 1 and 2 with respect to the increase in mesh elements. Figure 5 depicts the change in pressure with the number of elements. On evaluating the grid test results, it is obvious that velocity and pressure variations seem to stabilise after 390000 elements. Mesh with the former mentioned number of elements were considered for transient analysis of all the artery models. Pulsatile time-varying velocity graph at rest condition is shown in Figure 6(a). This is applied at the inlet of the abdominal aorta. Taking into consideration the peripheral resistance of the arteries at the downstream, pulsatile pressure shown in Figure $6(b)$ is applied at the outlets [32]. The pressure pulse at the infrarenal aorta and the distal portions of the renal artery are assumed to be $10-40 \mathrm{mmHg}$. The duration of a single pulse lasts for 9 seconds which 
was taken as the total simulation time for the transient analysis [33-36]. The total number of timesteps taken was 180, and the size of each time-step was taken as 0.005 seconds as determined from the time-step independent studies conducted. Properties of blood flow were borrowed from [32,37]. The analysis was carried out using the SIMPLE formulation technique with the value of residuals taken as $1 \times 10^{-5}$ for better convergence and solution accuracy [25]. Simulation of blood flow in these artery models will yield information regarding the effects of angulation on the renal artery- abdominal aorta junction.

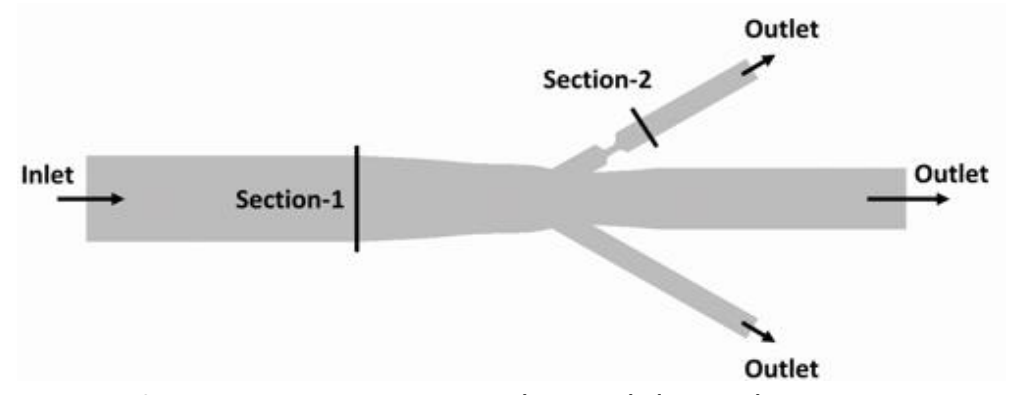

Fig. 3. Sections monitored in grid dependency test

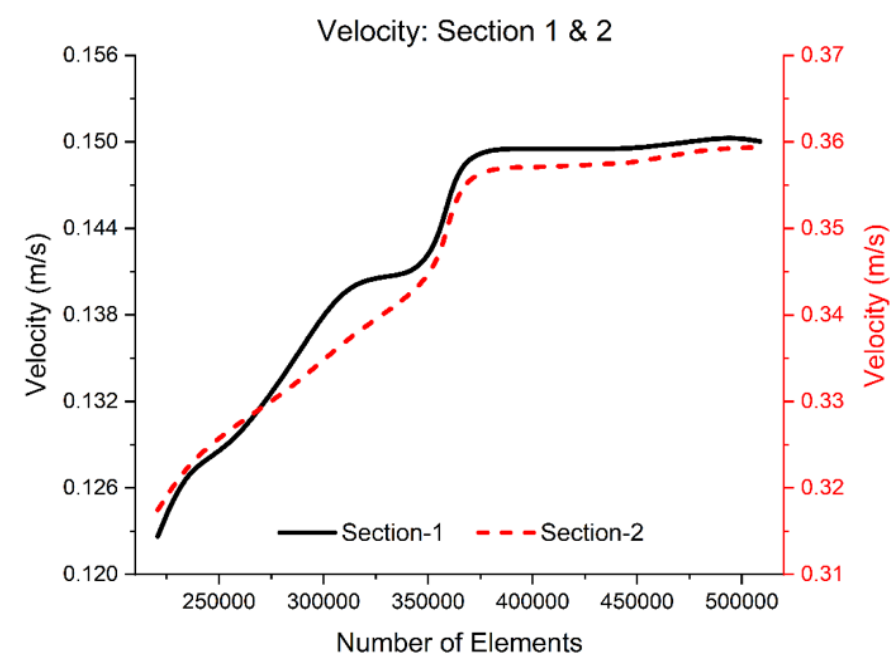

Fig. 4. Velocity distribution in section $1 \& 2$

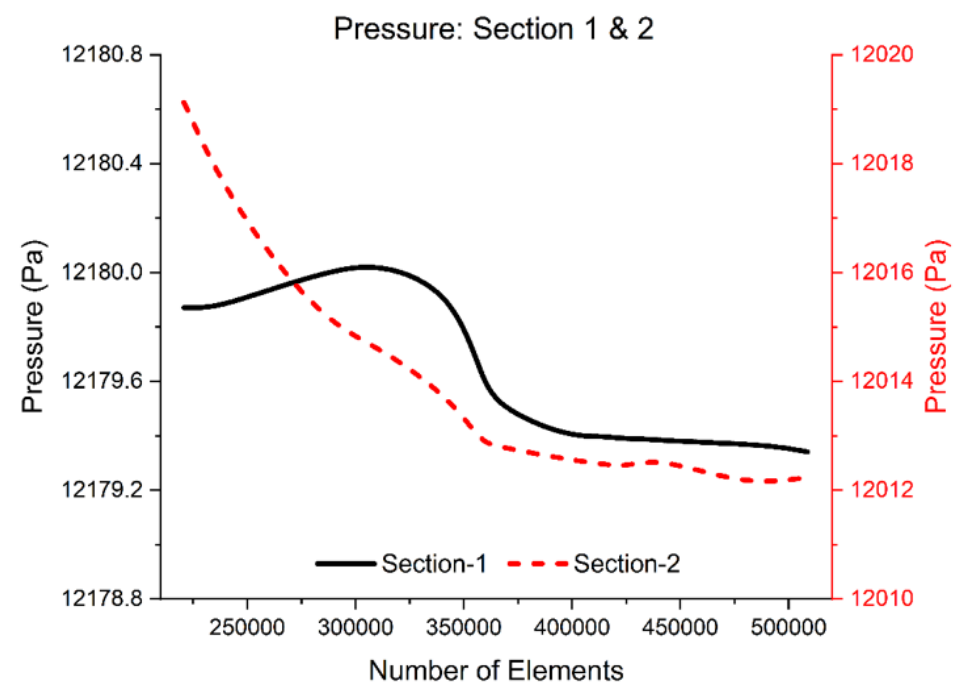

Fig. 5. Pressure distribution in section $1 \& 2$ 


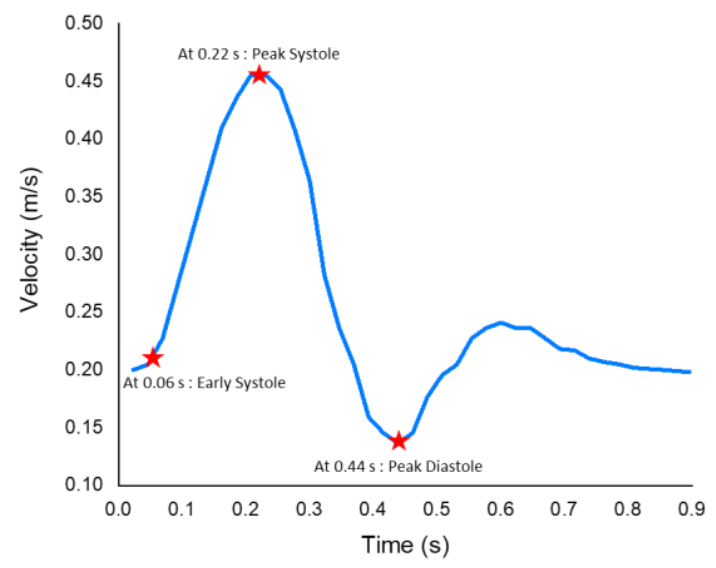

(a)

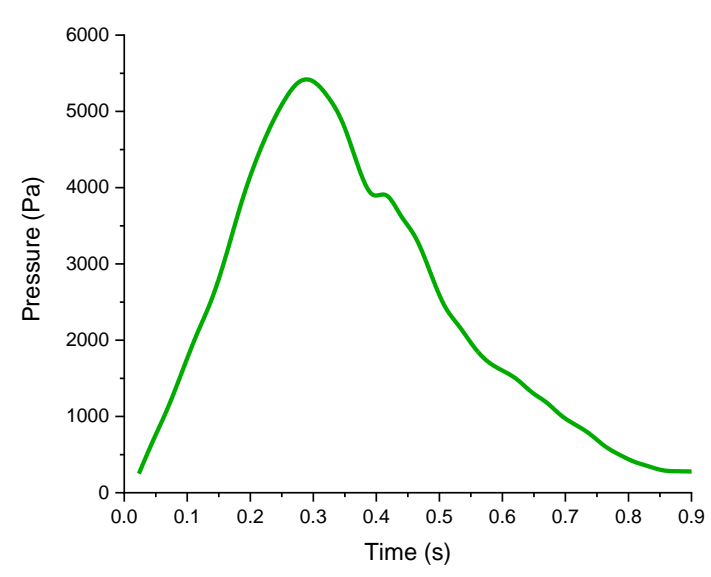

(b)

Fig. 6. Pulsatile nature of velocity at inlet shown in (a) and pulsatile nature of pressure at outlet shown in (b)

\section{Results and Discussion}

Transient analysis with pulsatile inlet velocity and pulsatile outlet pressure was simulated. Userdefined $C$ code was used to provide the pulsatile velocity and the pressure profile at the inlet and outlet boundary conditions, respectively [38]. Haemodynamic parameters such as velocity, wall pressure and wall shear stress were analysed at three different points in the pulse cycle. These three properties were compared at early systole ( 0.06 seconds), peak systole $(0.22$ seconds) and peak diastole ( 0.44 seconds) of the cardiac cycle.

The methodology of the present work conducted adheres to procedures in [25]. Prior to the CFD simulations, extensive grid tests were conducted in a similar approach, ensuring that the results obtained are reliable and accurate for use. This study acts in consequence of the previous study, albeit providing more information on the effects of angulation of the renal artery. Validation of the results obtained were done by comparing it with $[17,24,25]$. Consistency of the results with that of experimental observations was also ascertained in [39]. This confirms that the results of the CFD simulation are useful in predicting the flow through the abdominal aorta-renal artery bifurcations.

\subsection{Velocity}

Comparing the velocity contour plot given in Figure 7,8 and 9 of artery models with $30^{\circ}, 60^{\circ}$ and $90^{\circ}$ angulation respectively in three different phases of the cardiac cycle, it was seen that the flow patterns were very different. Blood flow in either of the renal artery was identical owing to the symmetrical nature of the artery geometry. At early systole, peak systole and at peak diastole, blood flow in either of the renal arteries with lower angles of bifurcation were scarce. This is primarily due to blood flow in the renal arteries getting impeded by the abdominal aorta [34,35]. Lower bifurcation angles make blood flow into the arteries more convenient than those with greater branching angles. Blood flow impinges on the distal wall of the renal arteries; making velocity at this region greater than that at the proximal wall region [25]. This lead to a flow recirculation zone near the proximal wall [24]. The length and the area of the flow recirculation zone fluctuated from early systole, peak systole and peak diastole. 


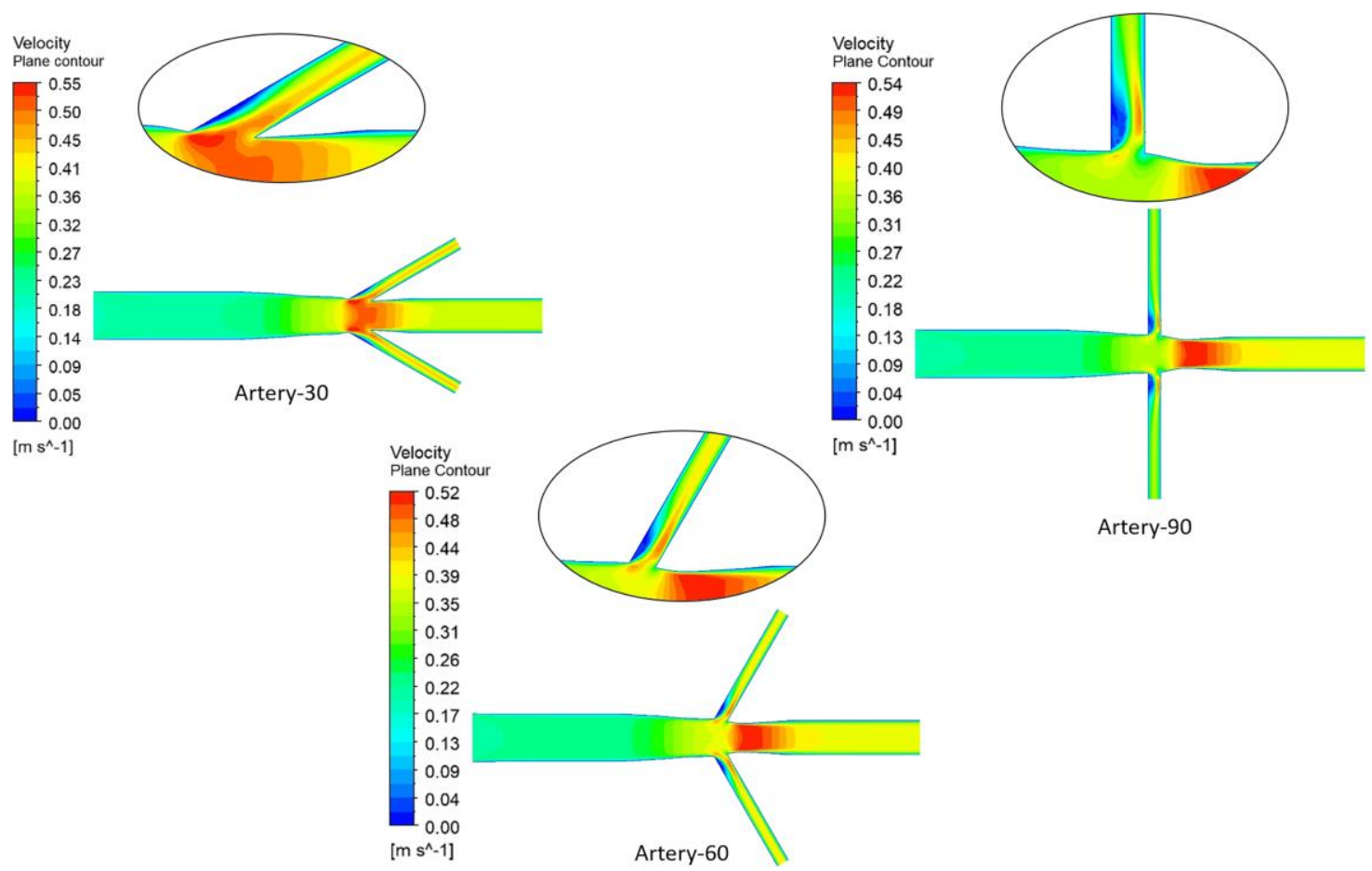

Fig. 7. Comparison of velocity contours of arteries with $30^{\circ}, 60^{\circ}$ and $90^{\circ}$ bifurcation angles at early systole
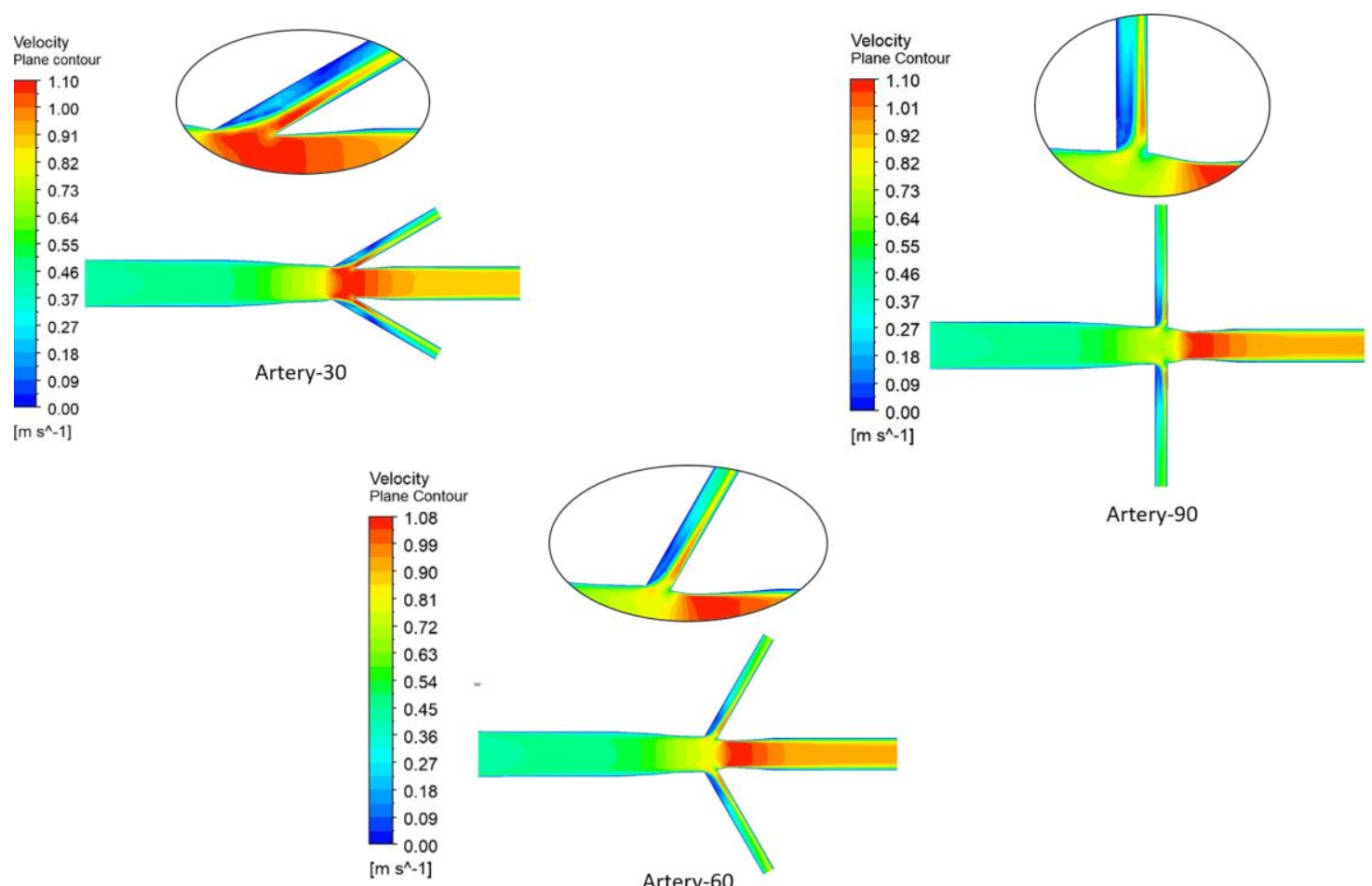

Artery-90

Artery-60

Fig. 8. Comparison of velocity contours of arteries with $30^{\circ}, 60^{\circ}$ and $90^{\circ}$ bifurcation angles at peak systole 


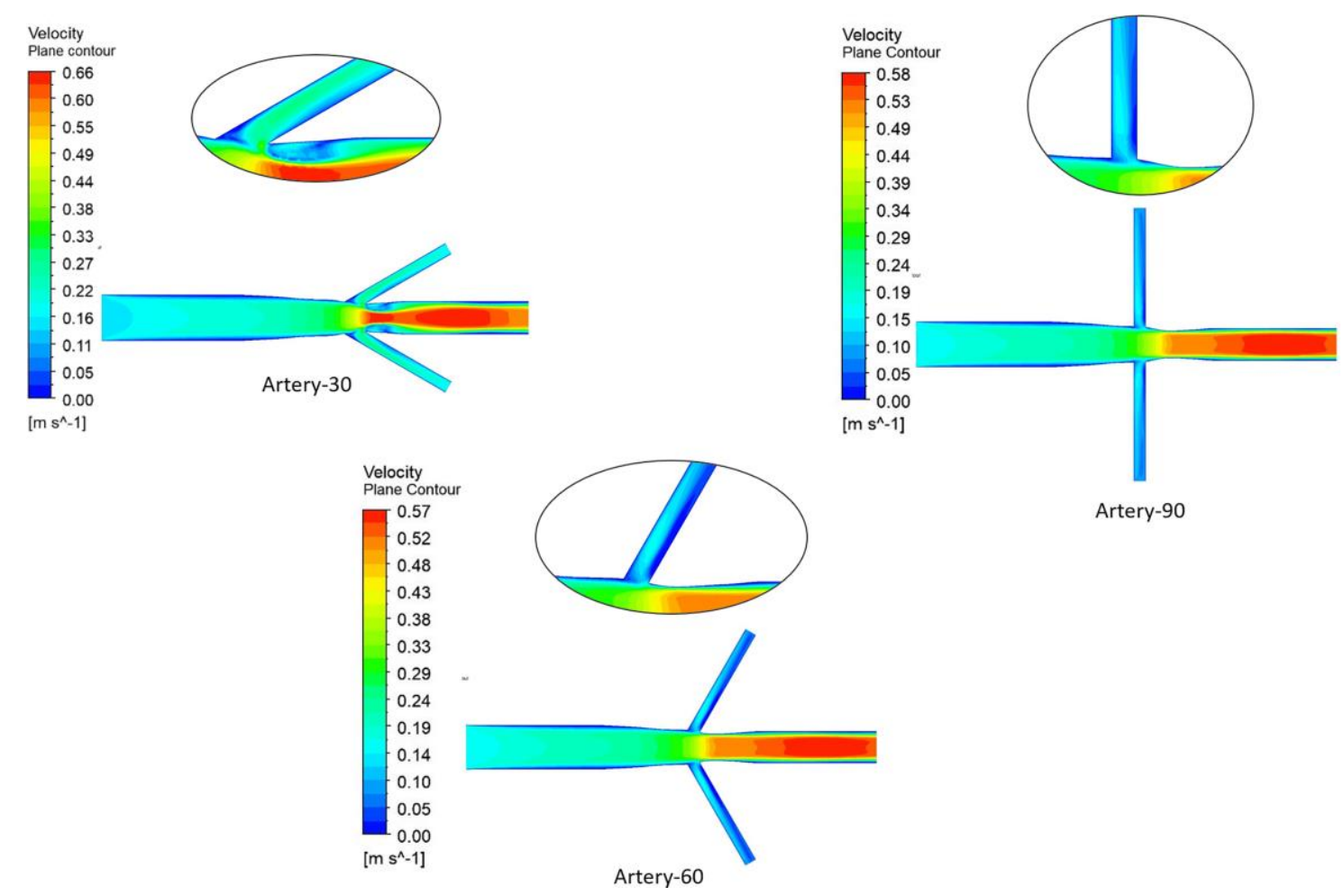

Fig. 9. Comparison of velocity contours of arteries with $30^{\circ}, 60^{\circ}$ and $90^{\circ}$ bifurcation angles at peak diastole

Further validation regarding flow recirculation was obtained from Figure 10, 11 and 12, where vector plots of the velocity profile of arteries with bifurcation angle $45^{\circ}$ and $75^{\circ}$ were compared. Recirculation was primarily observed adjacent to the proximal wall. Arteries with higher angulation were seen with higher areas of recirculation, as observed in [24]. Length and area of eddy formation were found to increase with angulation from early systole to peak systole. However, eddies were absent at peak diastole as total reversed the flow of blood was seen in the renal arteries. Additionally, changes in velocity at the wall have also led to variation in shear stresses, effecting the mass transfer between the fluid medium and the endothelium [25]. In such cases, by virtue of its geometry, pathological arteries at a higher branching angle $\left(\geq 60^{\circ}\right)$ with non-critical stenosis would progress to a critical stage, and the presence of an already higher stenosis grade, would lead to ischemic nephropathy.

Figure 13 depicts the velocity changes with respect to time at mid-section of the right renal artery for all the artery models. Comparing at early systole $(0.06 \mathrm{~s})$, peak systole $(0.22 \mathrm{~s})$ and peak diastole $(0.44 \mathrm{~s})$, velocity curve of the artery with $30^{\circ}$ angulation was much higher than the other models. It was then followed by the artery with $45^{\circ}$ bifurcation angle and then the other model. The above graph co-relates with the inferences obtained from studying the contour plot and vector plot given above. The depression at $0.22 \mathrm{~s}$ and $0.44 \mathrm{~s}$ indicates the presence of flow recirculation. Velocity was found to be the determining factor in the generation of these eddies as Figure 14 suggests minimal deviation in static pressure of the blood flow at the centre section of the renal arteries. 


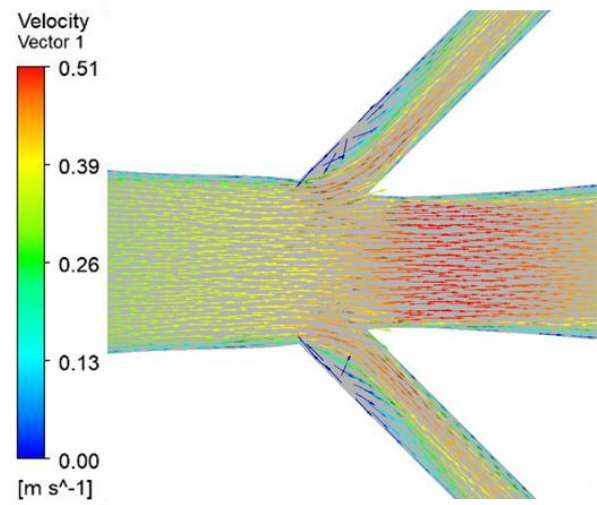

Artery-45

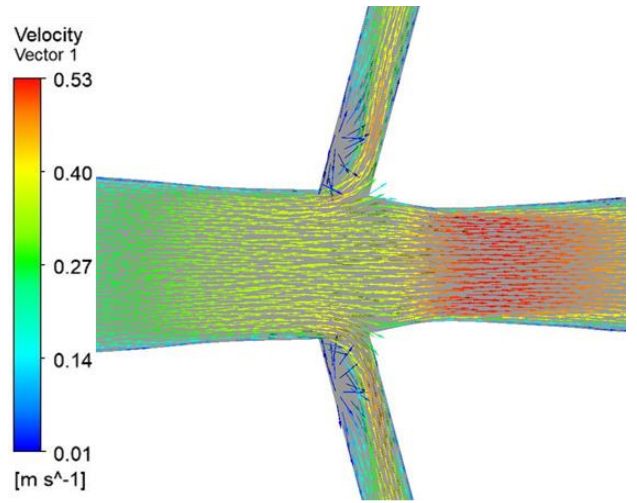

Artery-75

Fig, 10. Vector plots of arteries with $45^{\circ}$ and $75^{\circ}$ bifurcation angles at early systole

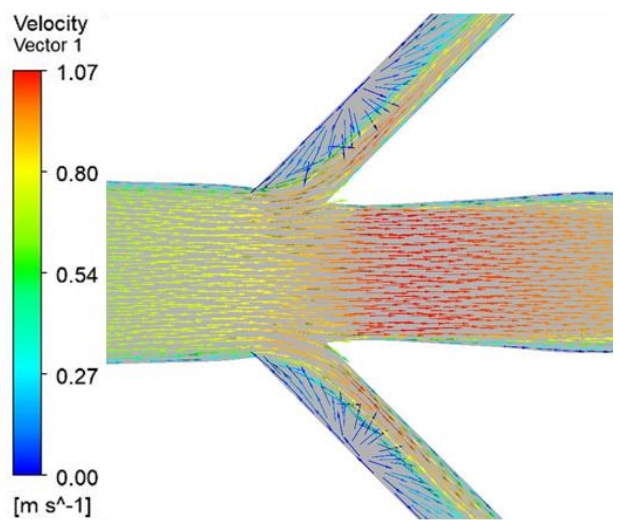

Artery-45

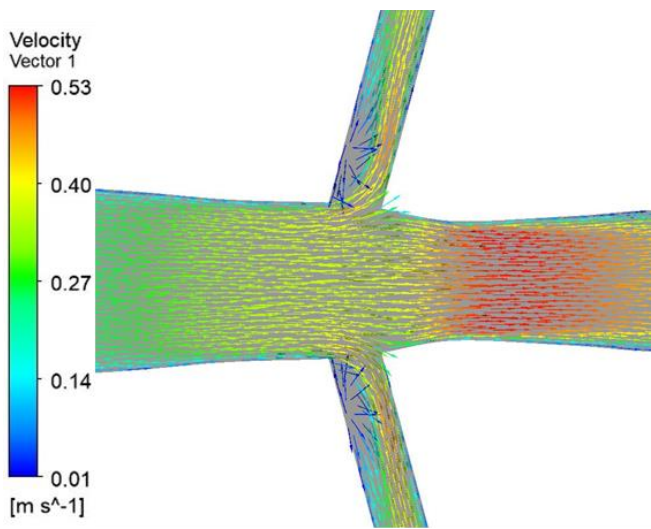

Artery-75

Fig. 11. Vector plots of arteries with $45^{\circ}$ and $75^{\circ}$ bifurcation angles at peak systole
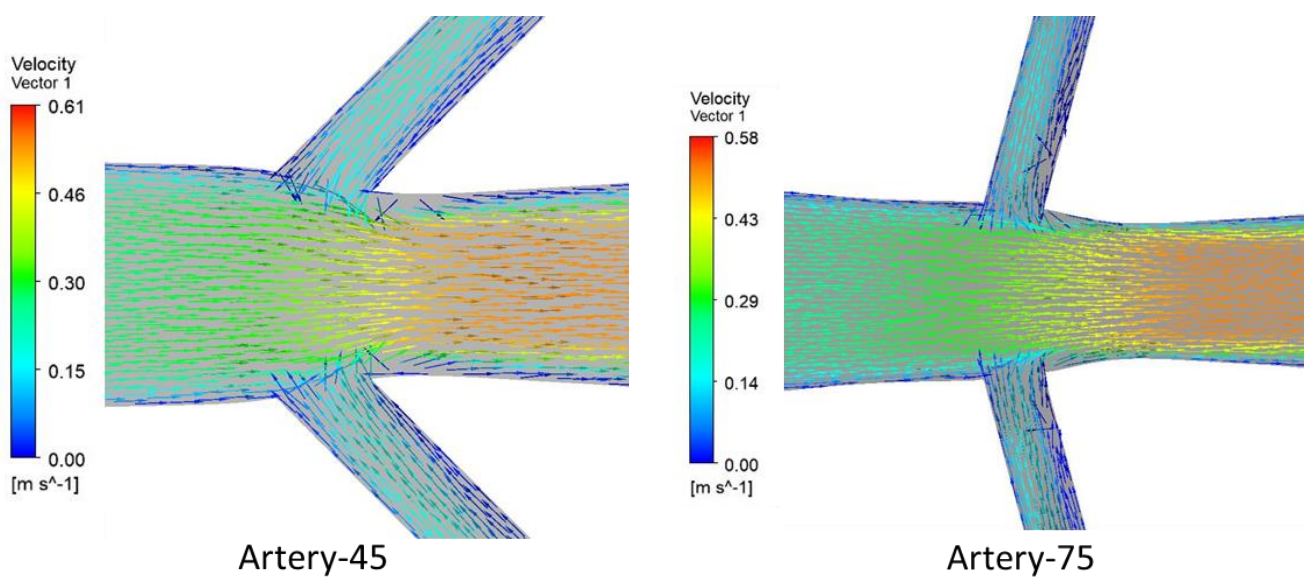

Fig. 12. Vector plots of arteries with $45^{\circ}$ and $75^{\circ}$ bifurcation angles at peak diastole 


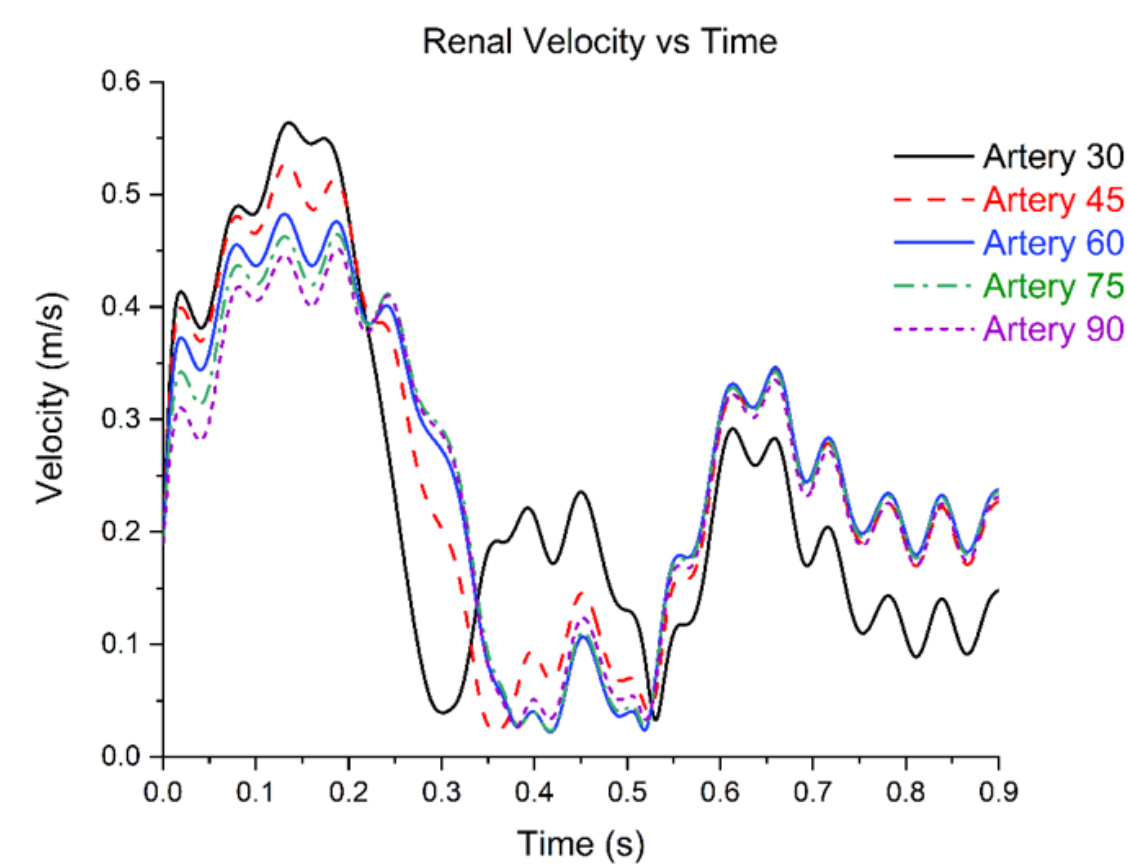

Fig. 13. Evolution of velocity at the mid-section of the renal artery

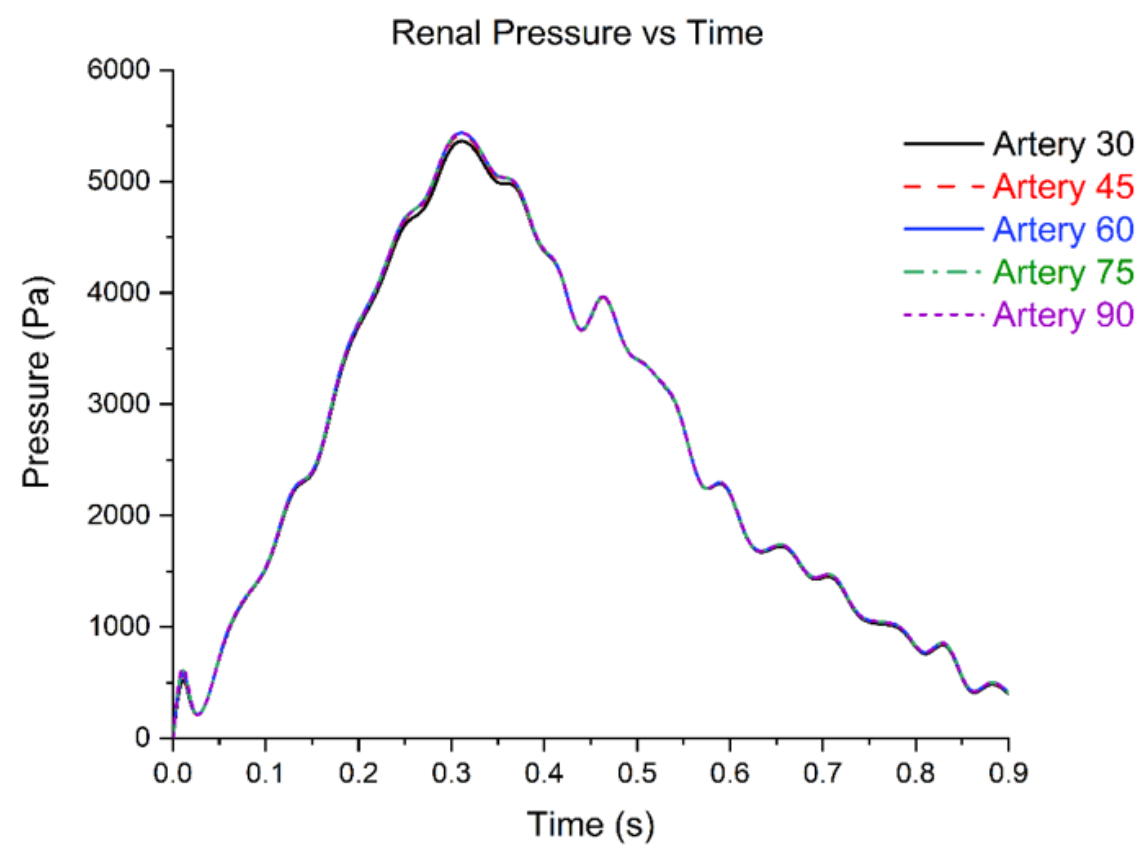

Fig. 14. Evolution of pressure at the mid-section of the renal artery

\subsection{Wall Pressure}

Figure 15 and 16 show the pressure contours at early and peak systole. There was a positive gradient of wall pressure along the length of the abdominal aorta, with mild pressure drops seen at the regions of renal artery bifurcation. The pressure at peak systole was roughly three times than that at the early systole stage. The pressure contour at the peak diastole condition is shown in Figure 17 , where there was negative pressure gradient along the length of the abdominal aorta, and the renal branches owing to increased amounts of reversed flow. Wall pressure is found to increase with increasing bifurcation angle throughout the cardiac cycle, as it was also the case in the experimental data obtained from [40]. At the Ostia, the pressure at the distal wall was higher than that at the 
proximal wall in the early and peak systole condition for all the artery models, with pressure increasing proportionally with bifurcation angles. However, it was not the case at the peak diastole condition. The variation in pressure gradient with respect to time as shown in the above graphs, aids in understanding the physiological significance of a given atherosclerotic lesion [41]. It has always been associated with the direction of blood flow; higher the magnitude of oscillations, greater is the extent of reversed flow; when large enough is believed to cause flow separation [40]. The presence of stenosis causes oscillation in the PD with the average pressure losses in the left renal arteries of all angulations were noted to be above $10 \mathrm{mmHg}$. This causes malfunction in the renin-angiotensinaldosterone system (RAAS), which is known to cause renal hypertension [42]. Therefore, patients with arterial vasculature at higher angulations have more chances of getting diagnosed with hypertension, in the event of severe plaque formation.
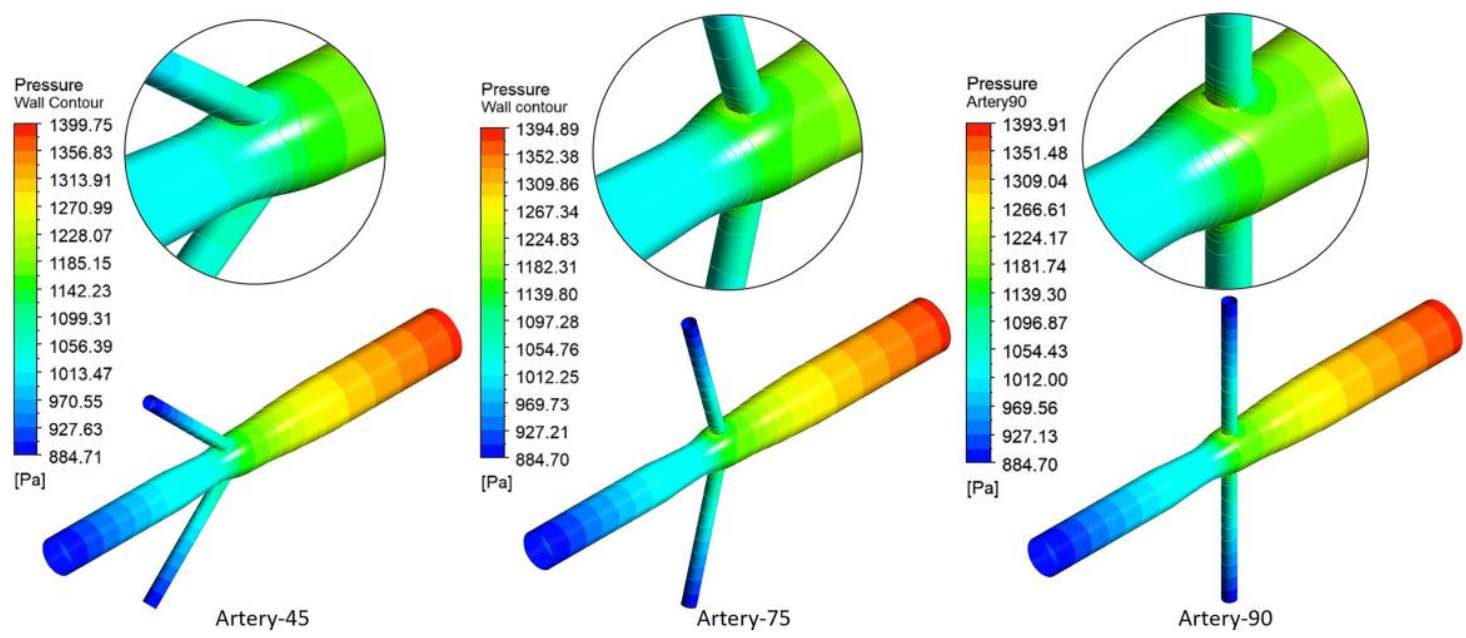

Fig. 15. Comparison of wall pressure contours of arteries with $45^{\circ}, 75^{\circ}$ and $90^{\circ}$ bifurcation angles at early systole

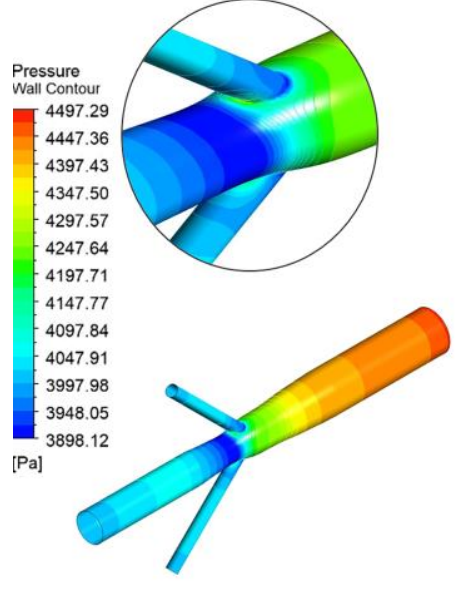

Artery-45
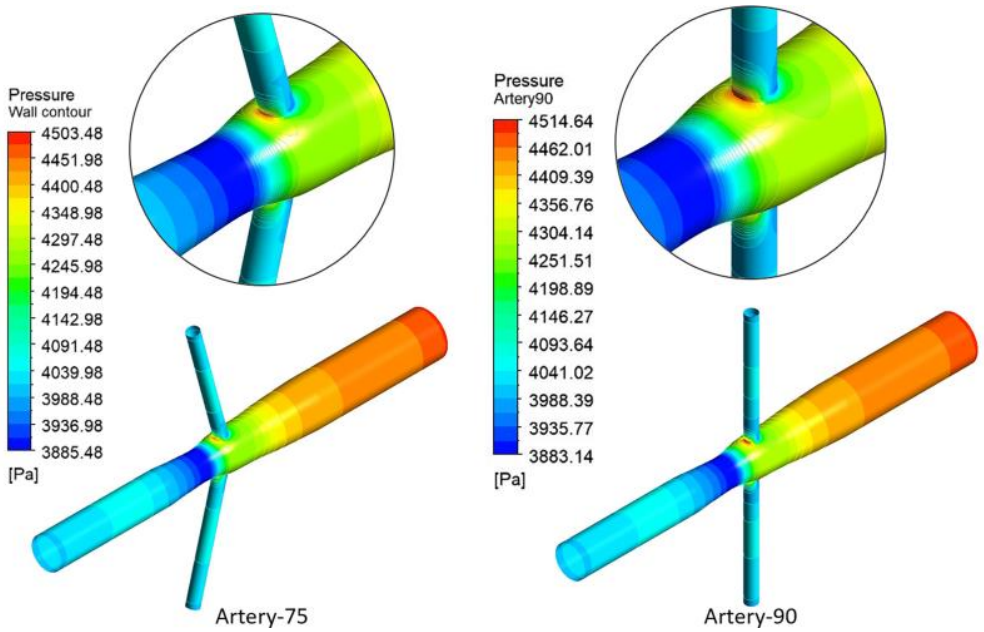

Fig. 16. Comparison of wall pressure contours of arteries with $45^{\circ}, 75^{\circ}$ and $90^{\circ}$ bifurcation angles at peak systole 


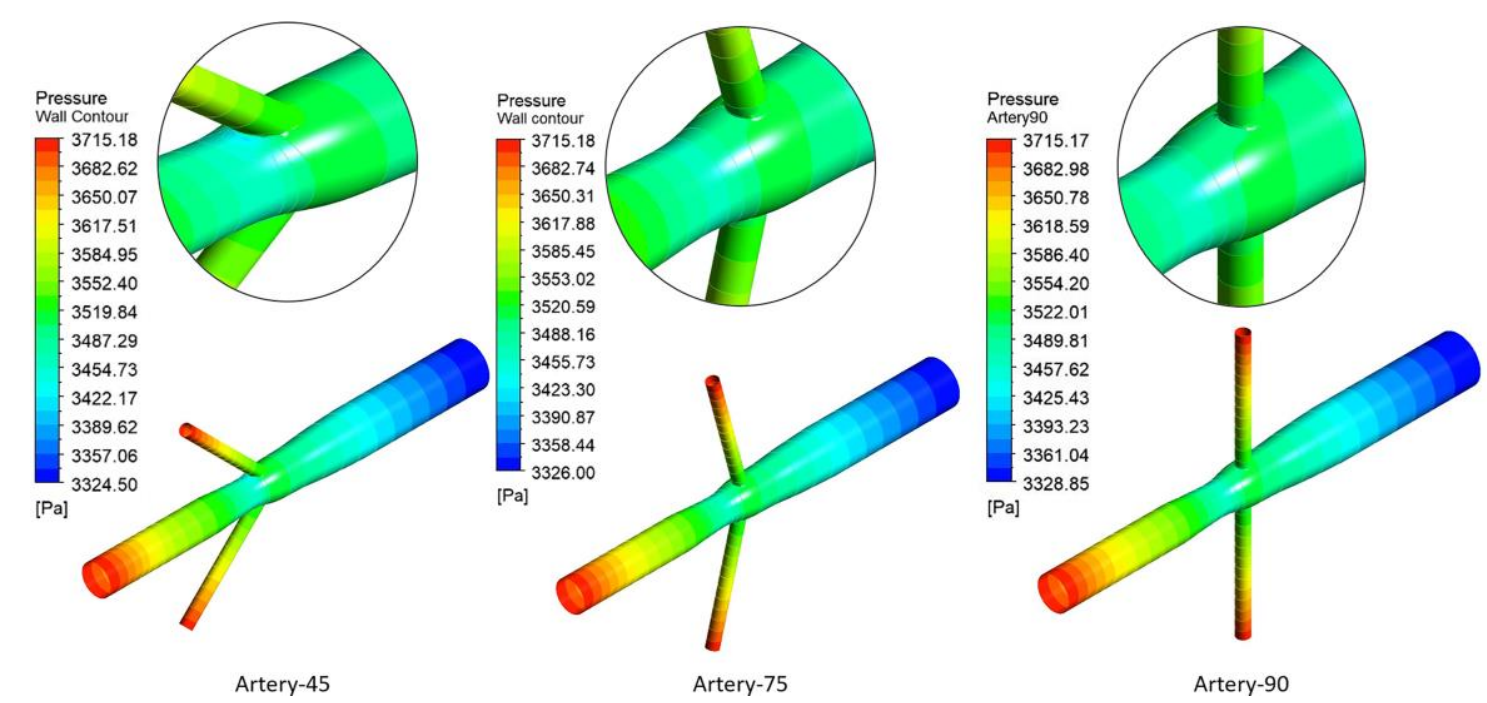

Fig. 17. Comparison of wall pressure contours of arteries with $45^{\circ}, 75^{\circ}$ and $90^{\circ}$ bifurcation angles at peak diastole

\subsection{Wall Shear Stress}

Figures 18, 19 and 20 show WSS contours for arteries with varying angulation at early systole, peak systole and peak diastole. WSS was seen to vary inversely with bifurcating angles. WSS varied proportionally with velocity as the highest values were seen at peak systole, followed by those at early systole and then at peak diastole. Throughout the pulse cycle, higher values of WSS were located at the Ostia, with distal wall experiencing higher stress than the proximal wall [17]. As angulation of the renal arteries increased, WSS throughout the wall of the artery decreased and became more localised at the infrarenal region. Low wall shear stress indicates that there is standing recirculation of blood in the region. This causes interactions between blood cells with the arterial walls, resulting in atherosclerosis [43]. Maximum WSS oscillations are seen the Ostia, making it one of the regions vulnerable to plaque formation [44]. The oscillations were much more prominent with an increase in angle of the renal artery. Distribution of shear stress on the arterial walls have always been linked with atherogenesis [32]. It is a very sensitive parameter as minimal changes in the shear stress value can have significant implications in the flow behaviour. Areas of low shear stress distributions like the proximal wall of the renal artery, are known to be sites of flow recirculation, which is linked to the onset of plaque formation [45]. Higher amounts of shear stress either at the throat of the stenosis or in areas subjected to incoming flow impingement at the junction such as the distal wall, often cause shear thinning in said regions and other regions downstream [40].

Figure 21 summarizes all the parameters discussed in one graph, wherein the normalised data of the properties were compared with renal arteries of different angulation. The maximum value of velocity at the Ostia for all angulations was observed at $0.22 \mathrm{~s}$. Formation of recirculation zones is evident as the velocity drops by $14 \%$ as the bifurcation angle increases from $30^{\circ}$ to $90^{\circ}$. Wall pressure at the region of the Ostia however, increases by $3 \%$ for the same trend. Wall shear stress at the junction sees a drastic drop as Artery-90 has a shear stress value $52 \%$ less than that of Artery-30. Thus, it quantifies the possibility of plaque formation in the abdominal aorta-renal artery junction of higher angulations. 


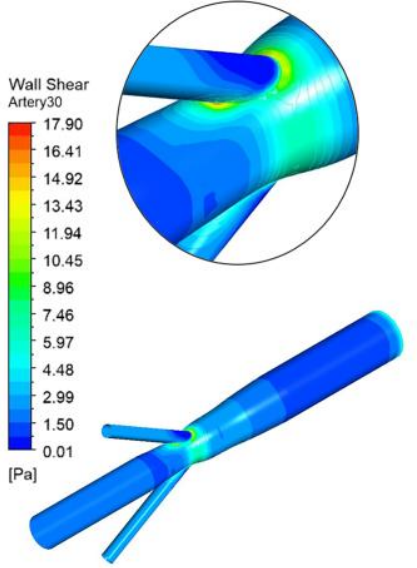

Artery-30

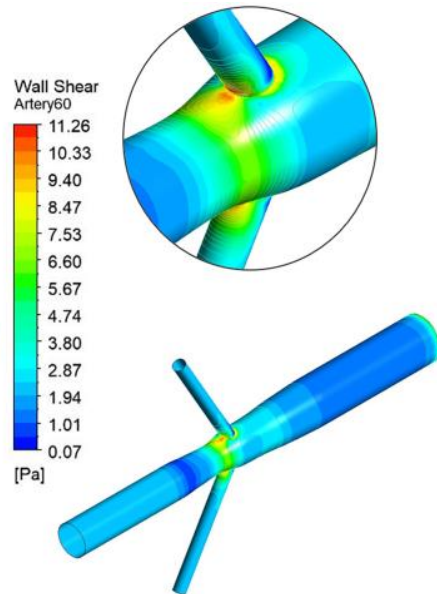

Artery-60

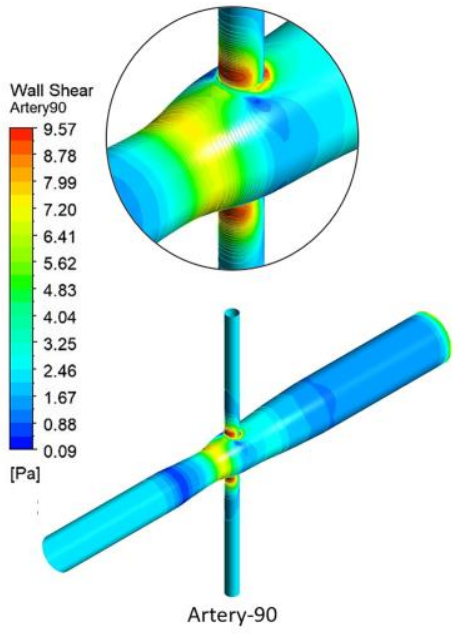

Fig. 18. Comparison of WSS contours of arteries with $45^{\circ}, 75^{\circ}$ and $90^{\circ}$ bifurcation angles at early systole

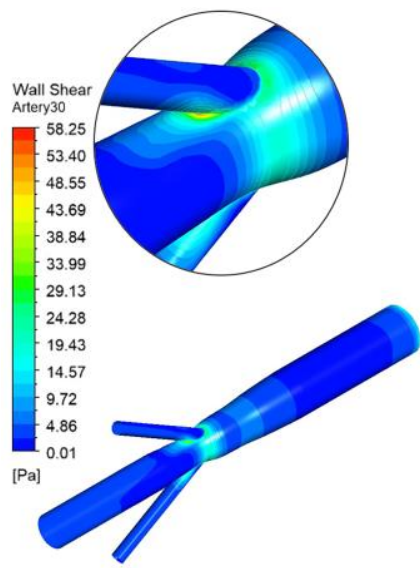

Artery-30

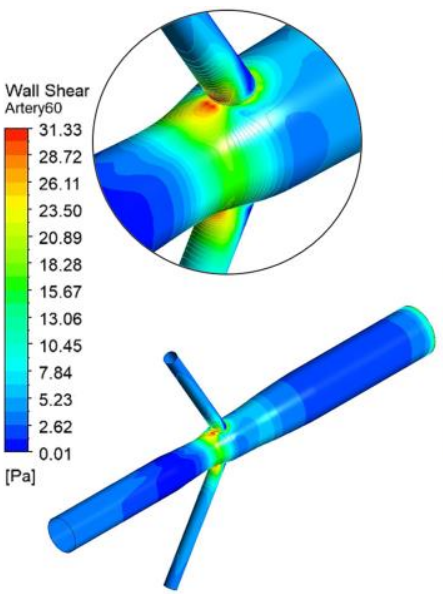

Artery-60

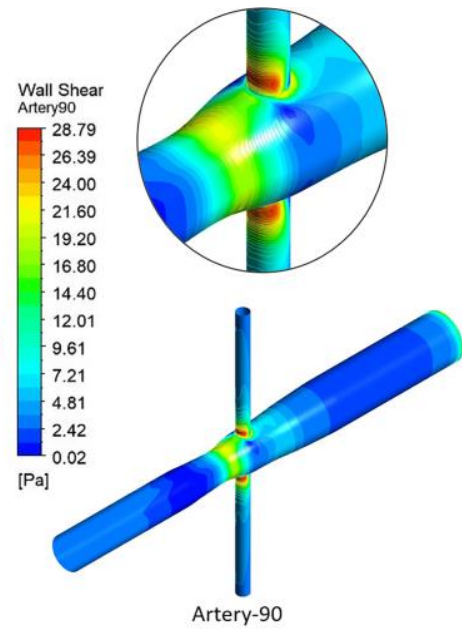

Fig. 19. Comparison of WSS contours of arteries with $45^{\circ}, 75^{\circ}$ and $90^{\circ}$ bifurcation angles at peak systole

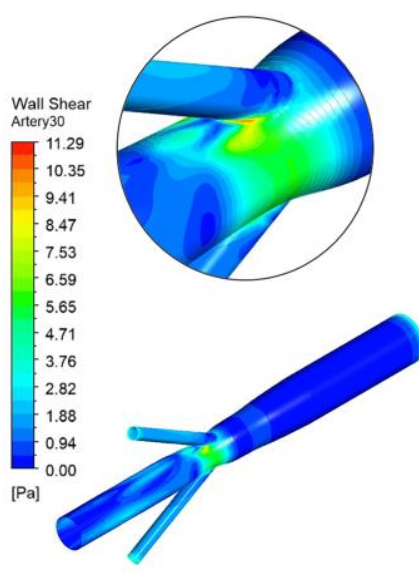

Artery-30

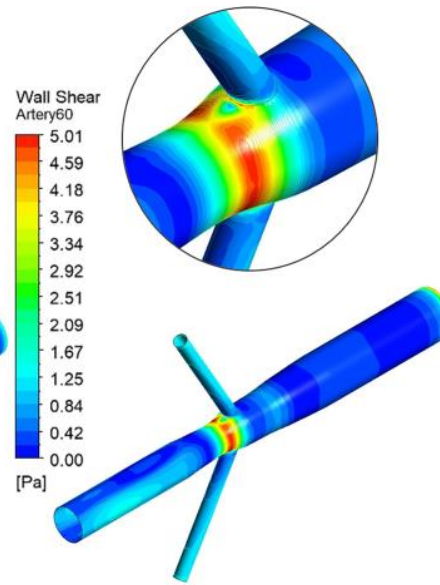

Artery-60

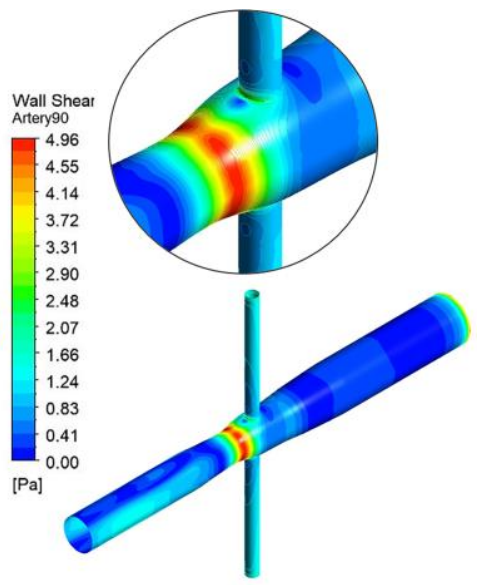

Artery-90

Fig. 20. Comparison of WSS contours of arteries with $45^{\circ}, 75^{\circ}$ and $90^{\circ}$ bifurcation angles at peak diastole 


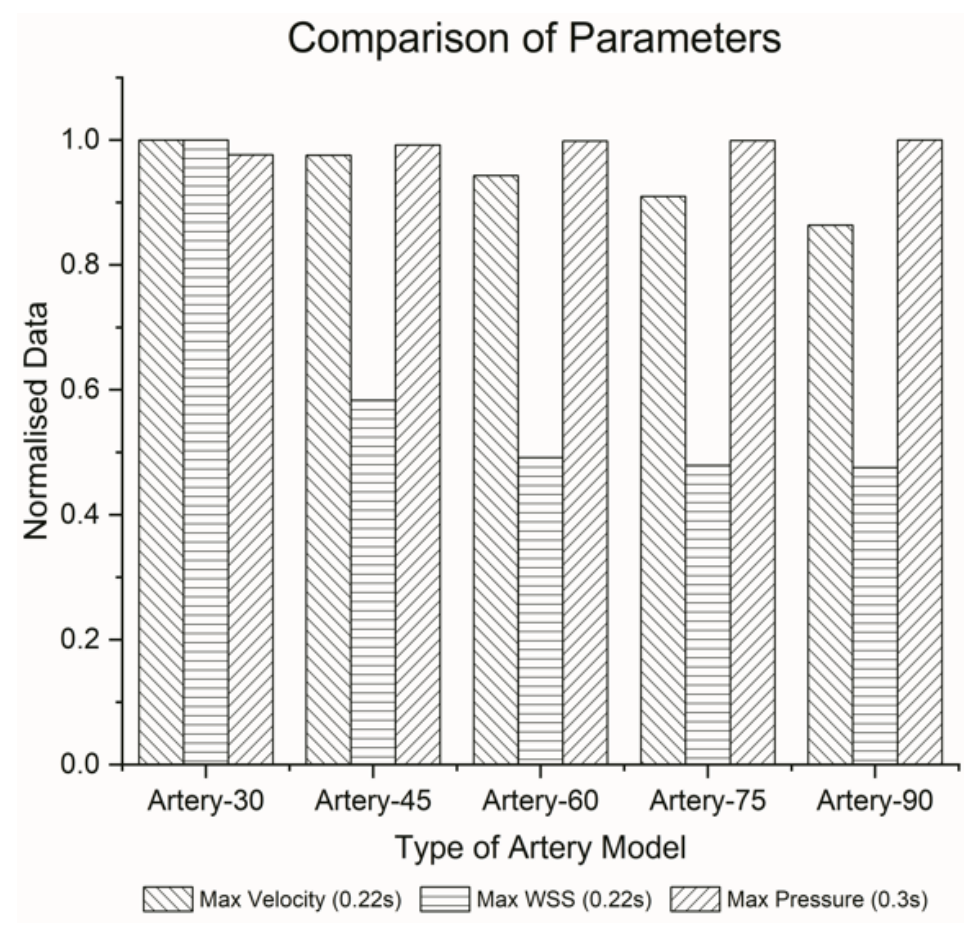

Fig. 21. Comparison of all the parameters for all the artery models

\section{Conclusions}

In the present study, numerical simulations are conducted on an idealistic, healthy artery model to observe the effects of angulation of renal arteries on the flow behaviour of blood. It can be used as a complementary tool that can assist doctors in analysing the factors causing atherosclerosis. The method used in this study can be used to assess arteries which are prone to atherosclerosis by virtue of its geometry. Angulation of renal arteries with the abdominal aorta is found to play a major role in recirculation of blood flow, oscillation of wall shear stress and wall pressure, which were among the haemodynamic parameters analysed. Velocity was found to be highest in the region of bifurcation. It varied throughout the cardiac cycle. Renal velocity was higher for arteries with smaller bifurcation angle and lowered for higher bifurcation angle as a result of flow getting impeded at the Ostia. Flow recirculations were more prominent in arteries with higher angulation. WSS was seen to reduce as bifurcation angle increased. For arteries with higher bifurcation angles, it tended to be localised at the infrarenal region and at the Ostia. Wall pressure varied inversely to velocity and WSS, with higher bifurcation angles resulting in higher wall pressure near the Ostia. The present study proved that arterial geometry is one of the factors influencing the formation of plaques at the walls. By analysing the blood flow through models with different bifurcation angles, it was concluded that arteries with higher angulation were found to be much more susceptible to atherosclerosis.

There were certain assumptions taken into consideration in the present work and requires further analysis to be suitable for practical applications. The artery wall is assumed to be rigid instead of elastic, making it unsuitable to fully resemble the physiological characteristics of an abdominal aortarenal artery junction. Further work can include CFD simulation in patient-derived geometries constructed from CT/MRI. Further study can be carried out on arteries with varying levels of stenosis and on patient-specific cases. 


\section{References}

[1] World Health Organization. "Hearts: technical package for cardiovascular disease management in primary health care." (2020).

[2] Marshall, Ian, Shunzhi Zhao, Panorea Papathanasopoulou, Peter Hoskins, and X. Yun Xu. "MRI and CFD studies of pulsatile flow in healthy and stenosed carotid bifurcation models." Journal of biomechanics 37, no. 5 (2004): 679687. https://doi.org/10.1016/j.jbiomech.2003.09.032

[3] Antiga, Luca. "Patient-specific modeling of geometry and blood flow in large arteries." Politecnico di Milano (2002).

[4] Joel, M. Elshin, and M. Anburajan. "3D Modeling of stenotic internal carotid artery treated with stent: a CFD analysis of blood." In Proceedings of the International Conference On Computer, Networks and Communication Engineering (Iccnce 2013), vol. 30, pp. 148-151. Atlantis Press, 2013.

[5] Fung, Y. C. "Microcirculation." In Biodynamics, pp. 224-289. Springer, New York, NY, 1984. https://doi.org/10.1007/978-1-4757-3884-1_5

[6] Caro, C. G., J. M. Fitz-Gerald, and R. C. Schroter. "Arterial wall shear and distribution of early atheroma in man." Nature 223, no. 5211 (1969): 1159-1161. https://doi.org/10.1038/2231159a0

[7] Steinman, David A. "Image-based computational fluid dynamics modeling in realistic arterial geometries." Annals of biomedical engineering 30, no. 4 (2002): 483-497. https://doi.org/10.1114/1.1467679

[8] Lee, Sang-Wook, Luca Antiga, J. David Spence, and David A. Steinman. "Geometry of the carotid bifurcation predicts its exposure to disturbed flow." Stroke 39, no. $8 \quad$ (2008): $2341-2347$. https://doi.org/10.1161/STROKEAHA.107.510644

[9] DiCarlo, Amanda L. "Investigation of Flow Disturbances and Multi-Directional Wall Shear Stress in the Stenosed Carotid Artery Bifurcation Using Particle Image Velocimetry." (2018).

[10] Zhao, S. Z., X. Y. Xu, A. D. Hughes, S. A. Thom, A. V. Stanton, B. Ariff, and Q. Long. "Blood flow and vessel mechanics in a physiologically realistic model of a human carotid arterial bifurcation." Journal of biomechanics 33, no. 8 (2000): 975-984. https://doi.org/10.1016/S0021-9290(00)00043-9

[11] Bai-Nan, Xu, Wang Fu-Yu, Liu Lei, Zhang Xiao-Jun, and Ju Hai-Yue. "Hemodynamics model of fluid-solid interaction in internal carotid artery aneurysms." Neurosurgical review 34, no. $1 \quad$ (2011): 39-47. https://doi.org/10.1007/s10143-010-0282-5

[12] Taylor, Charles A., Thomas JR Hughes, and Christopher K. Zarins. "Finite element modeling of three-dimensional pulsatile flow in the abdominal aorta: relevance to atherosclerosis." Annals of biomedical engineering 26, no. 6 (1998): 975-987. https://doi.org/10.1114/1.140

[13] Ku, David N., and Don P. Giddens. "Pulsatile flow in a model carotid bifurcation." Arteriosclerosis: An Official Journal of the American Heart Association, Inc. 3, no. 1 (1983): 31-39. https://doi.org/10.1161/01.ATV.3.1.31

[14] Jhunjhunwala, Pooja, Pramod Padole, and S. Thombre. "CFD analysis of pulsatile flow and non-Newtonian behavior of blood in arteries." MCB: Molecular \& Cellular Biomechanics 12, no. 1 (2015): 37-47.

[15] Caps, Michael T., Claudio Perissinotto, R. Eugene Zierler, Nayak L. Polissar, Robert O. Bergelin, Michael J. Tullis, Kim Cantwell-Gab, Robert C. Davidson, and D. Eugene Strandness Jr. "Prospective study of atherosclerotic disease progression in the renal artery." Circulation 98, no. $25 \quad$ (1998): $2866-2872$. https://doi.org/10.1161/01.CIR.98.25.2866

[16] Yim, Peter J., Juan R. Cebral, Ashley Weaver, Robert J. Lutz, Orlando Soto, G. Boudewijn C. Vasbinder, Vincent B. $\mathrm{Ho}$, and Peter L. Choyke. "Estimation of the differential pressure at renal artery stenoses." Magnetic Resonance in Medicine: An Official Journal of the International Society for Magnetic Resonance in Medicine 51, no. 5 (2004): 969977. https://doi.org/10.1002/mrm.20078

[17] Liang, Fuyou, Ryuhei Yamaguchi, and Hao Liu. "Fluid dynamics in normal and stenosed human renal arteries: an experimental and computational study." Journal of Biomechanical Science and Engineering 1, no. 1 (2006): 171182. https://doi.org/10.1299/jbse.1.171

[18] Shah Mohammed Abdul Khader, Azriff, Adi, Raghuvir Pai, Mohammed Zubair, Kamarul Arifin Ahmad, Zainuldin Ahmad, and Koteshwara Prakashini. "Haemodynamics study in subject-specific abdominal aorta with renal bifurcation using CFD-a case study." Journal of Advanced Research in Fluid Mechanics and Thermal Sciences 50, no. 2 (2018): 118-121.

[19] Sharifi, Alireza, and Hamid Niazmand. "Analysis of flow and LDL concentration polarization in siphon of internal carotid artery: Non-Newtonian effects." Computers in biology and medicine 65 (2015): 93-102. https://doi.org/10.1016/i.compbiomed.2015.08.002

[20] Xiong, Yan, Xuhong Wang, Wentao Jiang, Xiaobao Tian, Qingyuan Wang, Yubo Fan, and Yu Chen. "Hemodynamics study of a multilayer stent for the treatment of aneurysms." Biomedical engineering online 15, no. 2 (2016): 411420. https://doi.org/10.1186/s12938-016-0248-0 
[21] Shakeri, A. B., R. S. Tubbs, Mohammadali Mohajel Shoja, H. Nosratinia, and W. J. Oakes. "Aortic bifurcation angle as an independent risk factor for aortoiliac occlusive disease." Folia morphologica 66, no. 3 (2007): 181-184.

[22] Morbiducci, Umberto, Annette M. Kok, Brenda R. Kwak, Peter H. Stone, David A. Steinman, and Jolanda J. Wentzel. "Atherosclerosis at arterial bifurcations: evidence for the role of haemodynamics and geometry." Thrombosis and haemostasis 115, no. 03 (2016): 484-492. https://doi.org/10.1160/th15-07-0597

[23] Albert, Scott, Robert S. Balaban, Edward B. Neufeld, and Jenn Stroud Rossmann. "Influence of the renal artery ostium flow diverter on hemodynamics and atherogenesis." Journal of biomechanics 47, no. 7 (2014): 1594-1602. https://doi.org/10.1016/i.jbiomech.2014.03.006

[24] Ameenuddin, Mohammed, and Mohan Anand. "Effect of angulation and Reynolds number on recirculation at the abdominal aorta-renal artery junction." Artery Research $21 \quad$ (2018): 1-8. https://doi.org/10.1016/i.artres.2017.11.007

[25] Paszkowiak, Jacek J., and Alan Dardik. "Arterial wall shear stress: observations from the bench to the bedside." Vascular and endovascular surgery 37, no. 1 (2003): https://doi.org/10.1177/153857440303700107

[26] Johny, Cherian, S. M. Abdul Khader, B. Raghuvir Pai, Mohammad Zuber, K. A. Ahmed, and Zanuldin Ahmad. "Haemodynamic study of idealistic renal artery under different flow conditions." Journal of Computational Methods in Sciences and Engineering 19, no. 2 (2019): 541-552. https://doi.org/10.3233/JCM-181059

[27] Lee, Denz, and J. Y. Chen. "Pulsatile flow fields in a model of abdominal aorta with its peripheral branches." Biomedical Engineering: Applications, Basis and Communications 15, no. 05 (2003): 170-178. https://doi.org/10.4015/S1016237203000262

[28] Giannoglou, G. D., J. V. Soulis, T. M. Farmakis, D. M. Farmakis, and G. E. Louridas. "Haemodynamic factors and the important role of local low static pressure in coronary wall thickening." International journal of Cardiology 86, no. 1 (2002): 27-40. https://doi.org/10.1016/S0167-5273(02)00188-2

[29] Bernsdorf, Jörg, and Dinan Wang. "Non-Newtonian blood flow simulation in cerebral aneurysms." Computers \& Mathematics with Applications 58, no. 5 (2009): 1024-1029. https://doi.org/10.1016/i.camwa.2009.02.019

[30] Pai, Raghuvir, S. M. Khader, Anurag Ayachit, K. A. Ahmad, Md Zubair, V. R. K. Rao, and S. Ganesh Kamath. "Fluidstructure interaction study of stenotic flow in subject specific carotid bifurcation-a case study." Journal of Medical Imaging and Health Informatics 6, no. 6 (2016): 1494-1499. https://doi.org/10.1166/imihi.2016.1837

[31] Miranda, Amílcar IP, Paulo J. Oliveira, and F. T. D. Pinho. "Steady and unsteady laminar flows of Newtonian and generalized Newtonian fluids in a planar T-junction." International journal for numerical methods in fluids 57, no. 3 (2008): 295-328. https://doi.org/10.1002/fld.1626

[32] Chakravarty, S., and S. Sen. "Analysis of pulsatile blood flow in constricted bifurcated arteries with vorticity-stream function approach." Journal of medical engineering \& technology 32, no. 1 (2008): 10-22. https://doi.org/10.1080/03091900600700822

[33] Zhang, Weisheng, Yi Qian, Jiang Lin, Peng Lv, Kaavya Karunanithi, and Mengsu Zeng. "Hemodynamic analysis of renal artery stenosis using computational fluid dynamics technology based on unenhanced steady-state free precession magnetic resonance angiography: preliminary results." The international journal of cardiovascular imaging 30, no. 2 (2014): 367-375. https://doi.org/10.1007/s10554-013-0345-0

[34] Basri, Adi Azriff, Shah Mohammed Abdul Khader, Cherian Johny, Raghuvir Pai, Muhammad Zuber, Kamarul Arifin Ahmad, and Zanuldin Ahmad. "Numerical Study of Haemodynamics Behaviour in Normal and Single Stenosed Renal Artery using Fluid-Structure Interaction." Journal of Advanced Research in Fluid Mechanics and Thermal Sciences 51, no. 1 (2018): 91-98.

[35] Basri, Adi Azriff, S.M. Abdul Khader, Cherian Johny, Raghuvir Pai B, Mohammed Zuber, Zainuldin Ahmad, Kamarul Arifin Ahmad. "Effect of Single and Double Stenosed on Renal Arteries of Abdominal Aorta: A Computational Fluid Dynamics." CFD Letters 12, no. 1 (2020): 87-97.

[36] Taylor, Charles A., Thomas JR Hughes, and Christopher K. Zarins. "Effect of exercise on hemodynamic conditions in the abdominal aorta." Journal of vascular surgery 29, no. 6 (1999): 1077-1089. https://doi.org/10.1016/S07415214(99)70249-1

[37] Tang, Beverly T., Christopher P. Cheng, Mary T. Draney, Nathan M. Wilson, Philip S. Tsao, Robert J. Herfkens, and Charles A. Taylor. "Abdominal aortic hemodynamics in young healthy adults at rest and during lower limb exercise: quantification using image-based computer modeling." American Journal of Physiology-Heart and Circulatory Physiology 291, no. 2 (2006): H668-H676. https://doi.org/10.1152/ajpheart.01301.2005

[38] Abdul Khader, S. M., Anurag Ayachit, Raghuvir Pai, Mohammad Zubair, K. A. Ahmed, and V. R. Rao. "Study of the influence of Normal and High Blood pressure on normal and stenosed Carotid Bifurcation using Fluid-Structure Interaction." In Applied Mechanics and Materials, vol. 315, pp. 982-986. Trans Tech Publications Ltd, 2013. https://doi.org/10.4028/www.scientific.net/AMM.315.982

[39] ANSYS Release. "17.0 Documentation (2016)." ANSYS Company, Pittsburgh, PA. 
[40] Cho, Y. I., L. H. Back, and D. W. Crawford. "Experimental investigation of branch flow ratio, angle, and Reynolds number effects on the pressure and flow fields in arterial branch models." (1985): $257-267$. https://doi.org/10.1115/1.3138551

[41] Olin, Jeffrey W. "Atherosclerotic renal artery disease." Cardiology clinics 20, no. 4 (2002): $547-562$. https://doi.org/10.1016/S0733-8651(02)00091-7

[42] Yim, Peter J., Juan R. Cebral, Ashley Weaver, Robert J. Lutz, Orlando Soto, G. Boudewijn C. Vasbinder, Vincent B. $\mathrm{Ho}$, and Peter L. Choyke. "Estimation of the differential pressure at renal artery stenoses." Magnetic Resonance in Medicine: An Official Journal of the International Society for Magnetic Resonance in Medicine 51, no. 5 (2004): 969977. https://doi.org/10.1002/mrm.20078

[43] Motomiya, Mlneo, and Takeshi Karino. "Flow patterns in the human carotid artery bifurcation." Stroke 15, no. 1 (1984): 50-56. https://doi.org/10.1161/01.STR.15.1.50

[44] Lagana, Katia, Rossella Balossino, Francesco Migliavacca, Giancarlo Pennati, Edward L. Bove, Marc R. de Leval, and Gabriele Dubini. "Multiscale modeling of the cardiovascular system: application to the study of pulmonary and coronary perfusions in the univentricular circulation." Journal of biomechanics 38, no. 5 (2005): 1129-1141. https://doi.org/10.1016/i.jbiomech.2004.05.027

[45] Suo, Jin, John N. Oshinski, and D. P. Giddens. "Blood flow patterns in the proximal human coronary arteries: relationship to atherosclerotic plaque occurrence." Molecular \& Cellular Biomechanics 5, no. 1 (2008): 9. 